Document downloaded from:

http://hdl.handle.net/10251/123502

This paper must be cited as:

Galindo, J.; Climent, H.; Varnier, O.; Patil, CY. (2018). Effect of boosting system architecture and thermomechanical limits on diesel engine performance: Part II - Transient operation. International Journal of Engine Research. 19(8):873-885.

https://doi.org/10.1177/1468087417732264

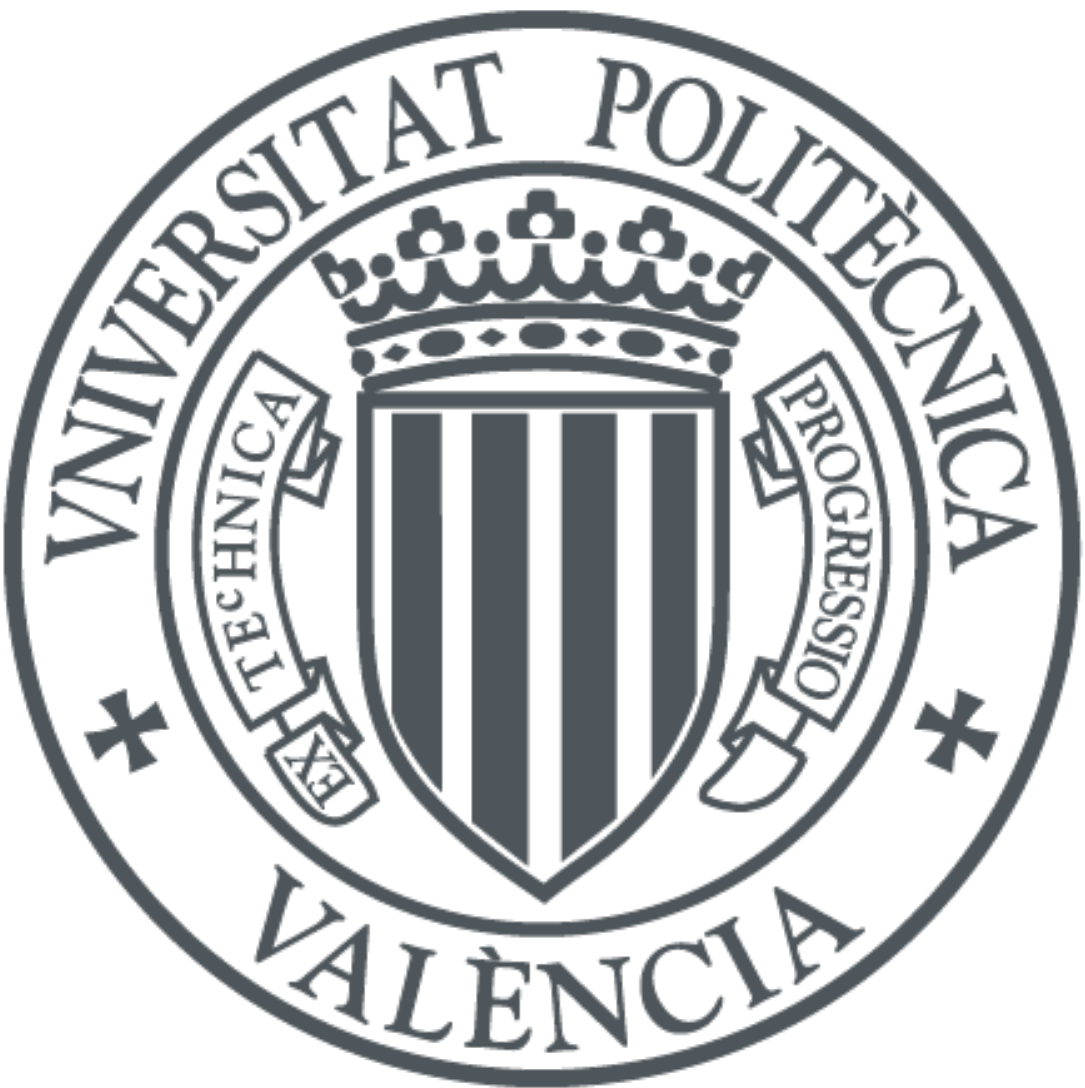

The final publication is available at

http://doi.org/10.1177/1468087417732264

Copyright SAGE Publications

Additional Information 


\title{
Effect of boosting system architecture and thermomechanical limits on diesel engine performance. Part-II: Transient Operation
}

\author{
Jose Galindo, Hector Climent, Olivier Varnier ${ }^{\dagger}$, Chaitanaya Patil ${ }^{*}$ \\ CMT-Motores Térmicos, Universitat Politècnica de València, Valencia 46022, Spain., \\ ${ }^{\dagger}$ Jaguar Land Rover ltd., UK., \\ *e-mail : chpa7@mot.upv.es
}

$07 / 11 / 2016$

\begin{abstract}
Nowadays, internal combustion engines developments are focused on efficiency optimization and emission reduction. Increasing focus on world hamonized way to determine the performance and emissions on WLTP cycles is demanding to optimize the engines within transient operations. To achieve these, downsized or downspeeded engines are required which can reduce fuel consumption and $\mathrm{CO}_{2}$ emission. However, these technologies ask for efficient charging system. This paper consist of study of diffrent boosting architectures(single stage and two stage) with combination of diffrent charging system like super-chatgers, e-boosters etc. A parametric study is been carried out with a $0 \mathrm{D}$ engine model to analyze and compare diffrent architectures on same base engine. The impact of thermomechanical limits, turbo sizes and other engine development options characterizations are proposed to improve Fuel consumption, maximum power and performance of the downsized/downspeede diesel engines during the transient operations.
\end{abstract}

\section{Introduction}

To charecterize the new turbocharging architectures, a comprehensicve study has been carried out with $0 \mathrm{D}$ engine model responding to specific objectives. The model consist of a phenomenological combustion model and a OD filling and emptying model. In the first part of this paper we have covered analysis of an engine and the boosting system peformance under steady state 
operations. In this paper, the results obtained in single stage operations will be first reported to characterize the turbolag of small turbochargers. Then, the results obtained in two-stage operations will be presented to determine the impacts of the main turbocharger on time responses and to analyze the transient behavior of eBooster and supercharger configurations.

\section{Methodology: Transient Operations}

The cold transient tests at $1000 \mathrm{rpm}$ have been simulated with the different boosting architectures forthree engine displacements. These transient cycles are critical for the charging systems due to low gas mass flows and thermal inertias. Time responses obtained under these transient operations are therefore quite representative of the performance of both engine and boosting architectures. In modern engines development, it is generally assumed that 'one second' represents a good time response to reach the maximum low-end torque starting from low load, while 'two seconds' corresponds to poor transient abilities. Between both times, transient responses can be judged acceptable or not according to the specific application. For the simulations, the pressure losses characteristics of Engine (from the Ist part of the paper) components have been employed on the 2.31 engine and then scaled on the 1.61 and 1.21 engines to obtain the same pressure drops under the corresponding gas mass flows. Compressor outlet and exhaust manifold temperatures have not been restrained in the calculations but specific control strategies have been implemented on the turbines actuators to avoid excessive exhaust manifold pressure (limitation fixed at 4.5 bar). The smoke limiter has been calibrated with a maximum fuel to air ratio (lambda) of 0.9 and advanced incylinder pressure limitations have been retained in the cylinders. 


\begin{tabular}{lcccc}
\hline & Type & $\begin{array}{c}\text { Wheel } \\
\text { diameter }[\mathrm{mm}]\end{array}$ & $\begin{array}{c}\text { Inertia } \\
{\left[10^{-6} \mathrm{~kg} / \mathrm{m}^{2}\right]}\end{array}$ & $\begin{array}{c}\text { Peak } \\
\text { efficiency [\%] }\end{array}$ \\
\hline turbine A & VGT & 35 & 4.32 & 65.5 \\
turbine A_30 & VGT & 30 & 1.29 & 63 \\
turbine A_25 & VGT & 25 & 0.43 & 60 \\
turbine A_20 & VGT & 20 & 0.11 & 56 \\
\hline Turbine 1 & FGT & 35.5 & 3.59 & 65.5 \\
Turbine 2 & FGT & 34 & 2.76 & 64.5 \\
Turbine 3 & FGT & 31 & 1.58 & 63.5 \\
Turbine 3_25 & FGT & 25 & 0.43 & 60 \\
Turbine 3_20 & FGT & 20 & 0.11 & 56 \\
Turbine 3_15 & FGT & 15 & 0.02 & 51 \\
\hline
\end{tabular}

Figure 1: turbine characteristics

\begin{tabular}{lccc}
\hline & $\begin{array}{c}\text { Wheel } \\
\text { diameter }[\mathrm{mm}]\end{array}$ & $\begin{array}{c}\text { Inertia } \\
{\left[10^{-6} \mathrm{~kg} / \mathrm{m}^{2}\right]}\end{array}$ & $\begin{array}{c}\text { Peak } \\
\text { efficiency [\%] }\end{array}$ \\
\hline Compressor A & 41 & 1.86 & 73.8 \\
Compressor A_34 & 34 & 0.71 & 72.8 \\
Compressr A_29 & 29 & 0.31 & 72.3 \\
\hline
\end{tabular}

Figure 2: compressor characteristics

\section{${ }_{45} 3$ Turbocharger Response}

As we know, turbolag phenomenon is influenced by three main factors which are the turbine swallowing capacity, both compressor and turbine efficiencies and turbocharger inertia. A sensitivity study has thus been carried out on these factors to quantify their influences on transient response. For the impact of swallowing capacities, the different turbines from figure 1 have been coupled to different compressors figure 2 and then connected to the 2.31 engine.

The transient results obtained in single stage operations are shown in figure 3. Even though 

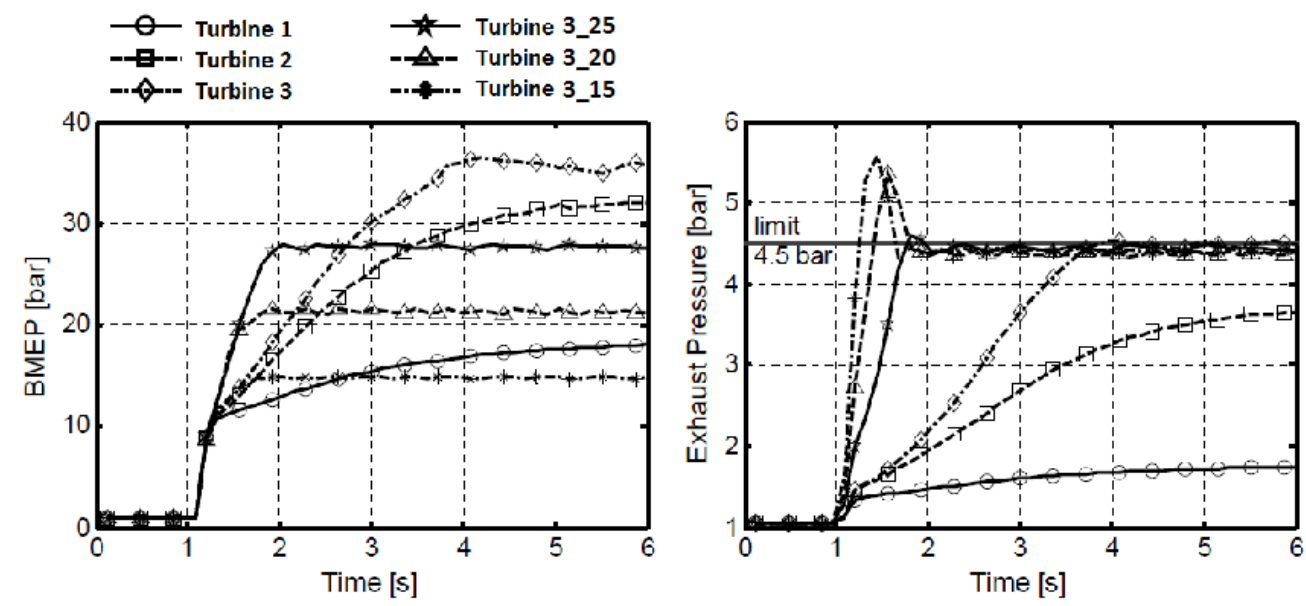

Figure 3: Influence of turbine swallowing capacity on transient performance during cold transient test cycles at $1000 \mathrm{rpm}$ on the 2.31 engine.

the turbine 1 is able to provide relatively high low-end torque in steady conditions, it can be observed how its power ability is too small under low gas mass flow and cold conditions to produce acceptable transient responses. Reducing the turbine effective section improves this situation and here a low end-torque objective of 30 bar BMEP can be reached in 3 seconds and 2 seconds with the turbine 2 and 3 respectively. At 20 bar BMEP, the turbine 3 swallowing capacity represents a good match for the 2.31 engine achieving the torque objective in around 1 second. This time response can further be enhanced to 0.6 second using the Turbine 3_25 but its small effective section leads rapidly to choked conditions restricting the maximum reachable BMEP to 27 bar due to exhaust manifold pressure limitations. With the turbine almost chocked, reducing even more the swallowing capacity strongly decrease the maximum BMEP and does not improve the time response. In fact at the beginning of the transient, the benefits of smaller turbine section are offset by higher engine backpressures. For a given engine displacement, 

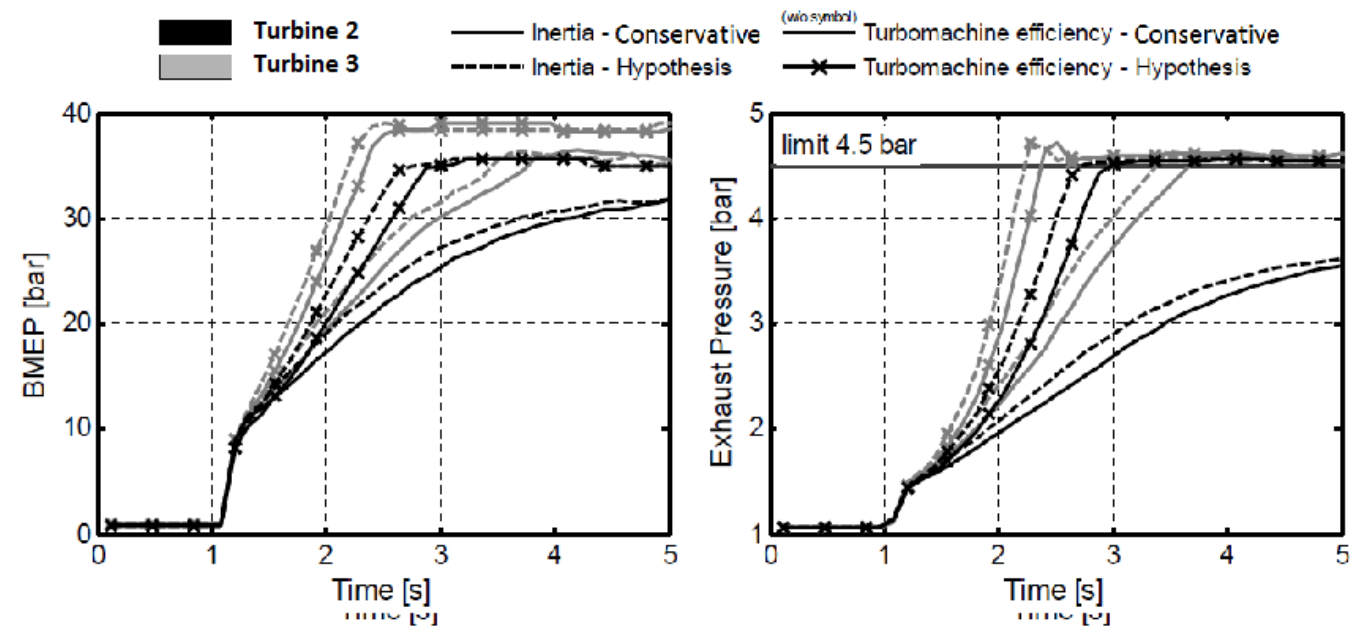

Figure 4: Influence of turbocharger efficiencies and inertia on transient performance during cold transient test cycles at $1000 \mathrm{rpm}$ on the 2.31 engine.

there is therefore a limit in turbine size reduction to maximize transient performance and here for the 2.31 engine an objective of 30 bar BMEP cannot be achieved in 1 second with small conservative turbine designs.

Regarding turbocharger efficiencies and inertias, variations of 10 points and $25 \%$ have been considered respectively. The simulations have been performed with the Turbine 2 and 3 fitted in the 2.31 engine. The results are shown in figure 4 . As these turbines already have relatively low inertias, it can be noticed that the use of advanced material to significantly reduce their inertia has limited consequences on transient responses. Here, benefits of only $0.2-0.3$ second have been obtained with $25 \%$ inertia reduction. However, the improvements in turbocharger efficiencies present important potential to enhance transient performance. In fact, increasing by 10 points the turbocharger efficiencies allow the time responses to be reduced by $50 \%$ and higher BMEP to be reached. With these efficiencies variations, the objective of 30 bar BMEP can now be achieved in 1 second using a turbine slightly smaller than the Turbine 3 . Small effective 
sections and efficient designs are therefore the fundamental combination to reduce turbo-lag phenomena. Analyzing the turbine requirements for the different engine displacements, it can be observed in figure 5 for an objective of 20 bar BMEP that the Turbine 3 provides a good transient response on the 2.31 engine but its swallowing capacity is too large to have some power abilities on the 1.61 engine. The corresponding time response is thus extremely slow and a $20 \%$ smaller turbine (Turbine_25) has to be developed to reach the torque objective within 1 second. On the 1.21 engine, the low gas mass flows are even more critical and a 35\% smaller turbine (Turbine 3_20) is required to reach the same performance. These scaling values can obviously be reduced if more efficient designs are developed in parallel to small swallowing capacities. For an objective of 30 bar BMEP.

efficiencies improvements are also essential and the trends underlined on the 2.31 engine can be generalized to the other engine displacements. So, turbines slightly smaller and significantly more efficient than the ones retained for the 20 bar BMEP objective need to be developed to reach this power level within 1 second. With VGT turbines, it can be noticed for the 2.31 engine that the smallest VGT available in the automotive market takes the same time to reach 20 bar BMEP as the smallest FGT. In fact, the benefits of smaller swallowing capacity obtained in closed position are offset by lower efficiency and higher inertia. Applying to the VGT the scaling factors previously defined for the FGT, this effect can also be verified for the 1.61 and 1.21 engines where the turbine A_30 and turbine A_25 produce similar time responses as the Turbine 3_25 and Turbine 3_20 respectively. At 20 bar BMEP, fitting a VGT in the HP stage presents thus little interest for the 2.31 engine but, for other engine displacements, the bigger wheel diameters involved can justify its use to reduce the efforts in small turbine designs development (wheel diameter differences of around 5mm). For higher BMEP, VGT are progressively open at the end of the transient to limit choked conditions adapting their swallowing capacity to the gas mass flows, so no power is lost through a wastegate. Transient performances are therefore 

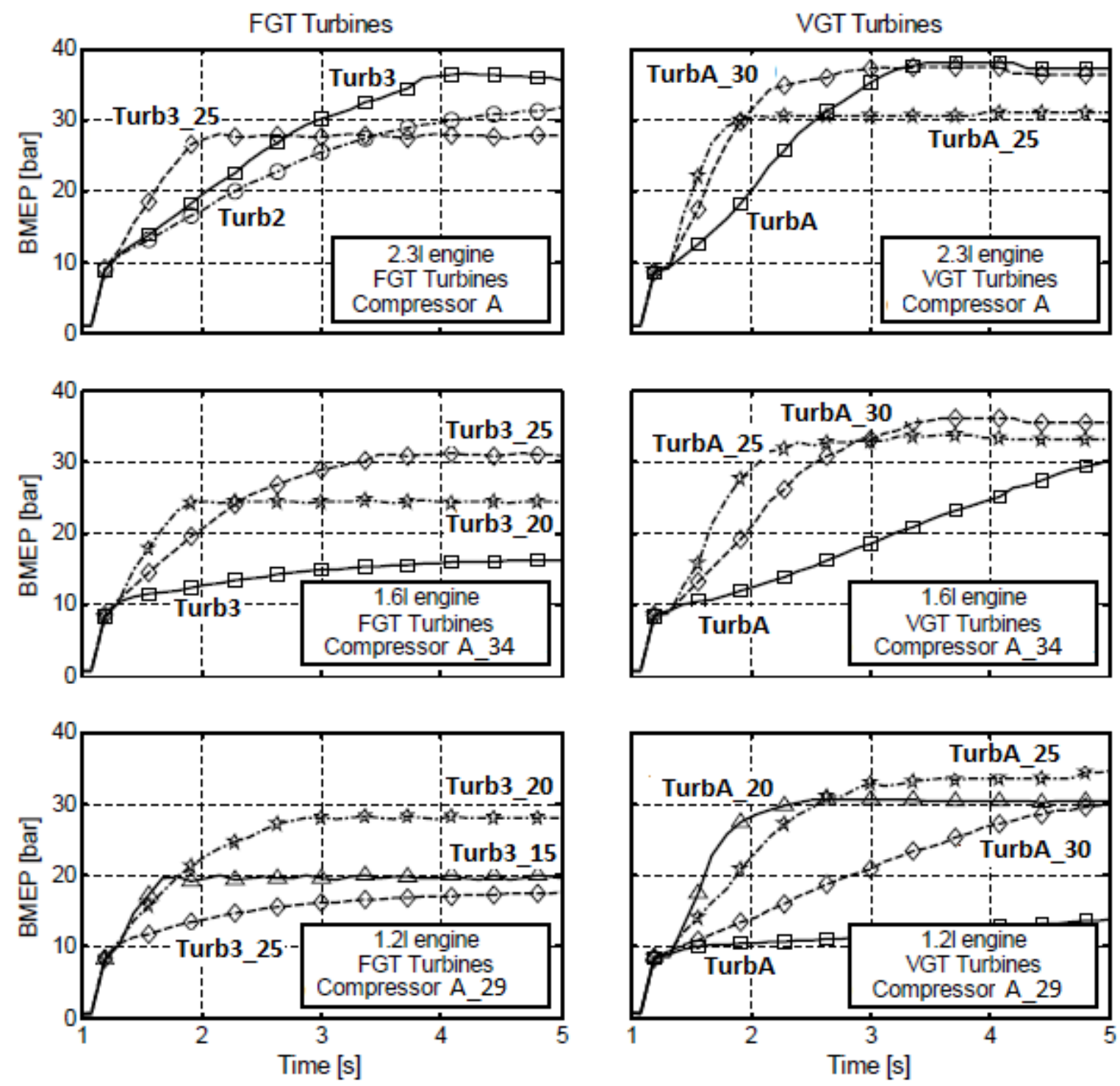

Figure 5: Turbine requirements to fulfill transient performance objectives in downsizeddownspeeded engines during cold transient test cycles at 1000rpm. efficiencies 
enhanced with VGT and efficiencies improvements are less critical than for FGT. In that way, the objective of 30 bar BMEP within 1 second can be achieved with conservative turbine designs Turbine A_30, turbine A_25 and turbine A_20 for the 2.31, 1.61 and 1.21 engines respectively) or with the VGT defined at 20 bar BMEP increasing relatively their efficiencies. The use of VGT at this power level can thus reduce development efforts not only in small effective sections but also in highly efficient designs.

\section{Two-Stage Performance}

\subsection{Two Stage Turbocharging Architecture}

In a two-stage turbocharging architecture, the main turbocharger can also have some abilities to produce boost at low engine speeds depending on its minimum swallowing capacity and VGT actuator strategies. This boost production has an impact on the second turbocharger operating conditions and on the whole transient performance. To illustrate these effects, simulations have been realized on the 2.31 engine with a FGT turbine 3 in the HP stage (wastegate closed) and a e-booster in the LP stage. A relatively small turbocharger has especially been retained in the LP stage to increase boost abilities at low speeds and amplify the main turbocharger influences. The results are shown in figure 6 where the transient responses obtained in two stage operations varying VGT position are compared to the response previously obtained in single stage operations with the same HP turbocharger. As it can be observed, the fastest transient is achieved in single stage operations when the small turbocharger works alone without any interactions from the LP stage. In two stage operations, even though 50\% to $100 \%$ VGT open- ings produce here similar results, the time responses increase closing the VGT as more energy is recovered by the main turbocharger.

This behavior is explained in figure 7 with the different operating conditions plotted in the characteristics maps. Increasing the main turbocharger work increases the gas density in the 

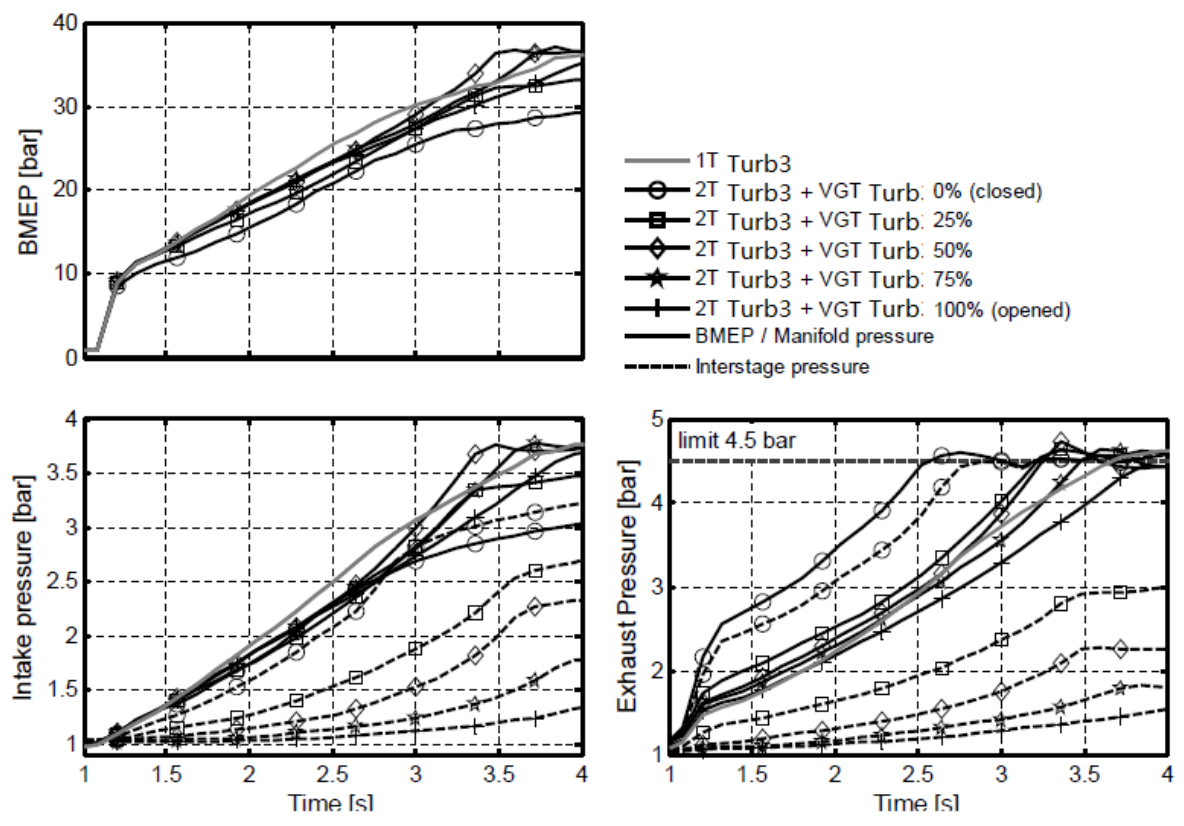

Figure 6: Effect of main turbocharger matching and VGT actuator strategies on transient performance (cold transient test cycles at 1000rpm on the 2.31 engine).

HP stage. The adapted gas mass flows are therefore reduced in the second turbine and, having a given swallowing ca- pacity, its power ability is lowered. This decrease of boost in the HP stage is more or less offset by the main turbocharger but, as the LP stage has a higher inertia, transient responses are deteriorated. So, the VGT has to be main- tained in an open position to optimize the transient responses in a two-stage turbocharging configuration equipped with a VGT in the LP stage. Comparing the results obtained at 100\% VGT opening with those obtained in single stage operations, slight differences exist here between both time responses be- cause the main turbocharger has a relatively small matching and the VGT produced some work even in full open position. With a bigger matching more adapted to this engine displacement, theses differences would be insignificant. So, the conclusions found in the previous section are also valid in two-stage operations and the development of small high efficient turbines stay critical to fulfill the performance requirements of future downsized-downspeeded engines. 


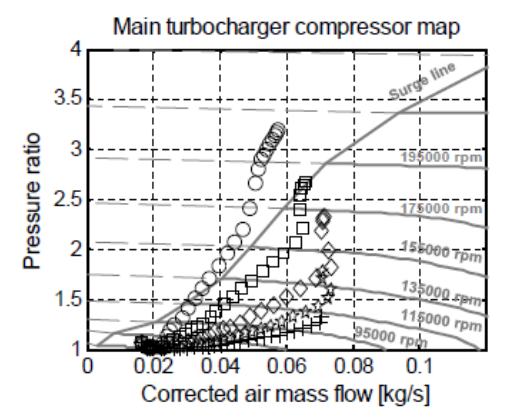

\begin{tabular}{llll}
\hline & Compressor/ turbine map \\
\hline & $2 T$ & FGT Turb3 + VGT Turb & $0 \%$ (closed) \\
& $2 T$ & FGT Turb3 + VGT Turb & $25 \%$ \\
$\diamond$ & $2 T$ & FGT Turb3 + VGT Turb & $50 \%$ \\
+ & $2 T$ & FGT Turb3 + VGT Turb & $75 \%$ \\
+ & $2 T$ & FGT Turb3 + VGT Turb & $100 \%$ (opened)
\end{tabular}

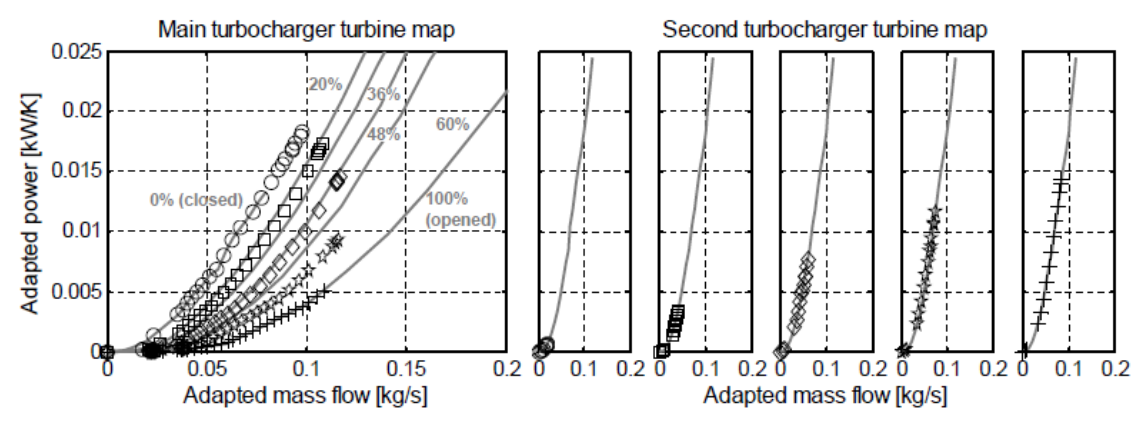

Figure 7: Interactions between HP and LP turbochargers during transient operations as a function of main turbocharger matching and VGT actuator strategies (cold transient test cycles at $1000 \mathrm{rpm}$ on the 2.31 engine).

\subsection{Two-Stage E-booster Architecture}

In a $2 \mathrm{~T}$ eBooster configuration, transient responses depend on the electric power supplied by the vehicle network and on the turbocharger boost abili- ties. As there is no interaction between the HP and LP stages in the exhaust side, the VGT is maintained in a closed position to optimize the turbine work production. According to the turbocharger matching, this position can be the closest VGT opening to generate the maximum power with the smallest tur- bine swallowing capacity, or the VGT opening that maximizes boost pressure preventing compressor surge. To analyze the main characteristics of $2 \mathrm{~T}$ eBooster architecture responses, calculations have been carried out on the 2.31 engine with a $4 \mathrm{~kW}$ eBooster. For the eBooster, the compressor inertia has been doubled to simulate representative eBooster accel- erations considering also a rough motor inertia [150, 247]. The results obtained under full eBooster electric power are shown 

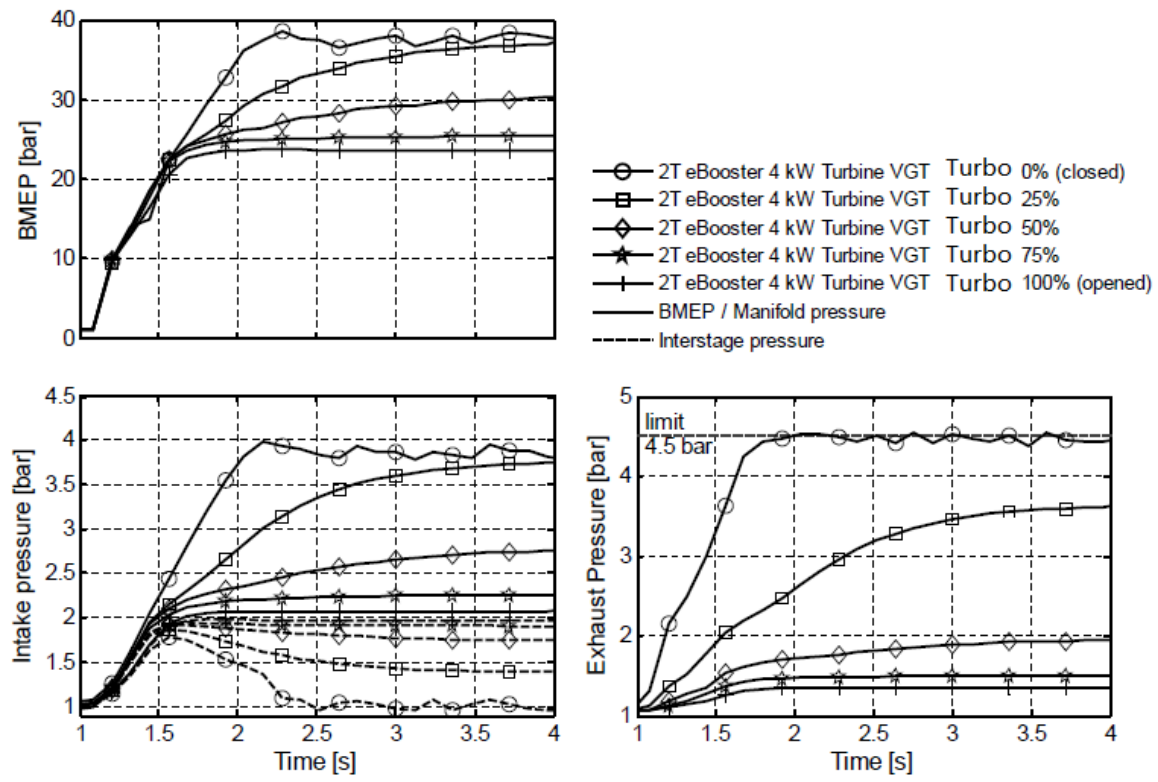

Figure 8: $2 \mathrm{~T}$ eBooster architecture transient responses as a function of turbocharger boost abilities during cold transient test cycles at 1000rpm on the 2.31 engine.

in figure 8. The VGT position has been varied here to represent different turbocharger boost abilities at low speeds. Using a relatively small matching, it has to be noticed that the main compressor may get into surge for the closest VGT openings (see figure 9).

Regarding the intake pressure built-up, the transient response can be di- vided in two different parts. First, the eBooster provides the boost correspond- ing to the electric power in approximately 0.5 second. Then, if the turbine can produce some power under these low gas mass flows, the turbocharger will continue to accelerate according to its efficiencies, inertia and swallowing ca- pacity. However, the resultant intake manifold pressure is not proportional to the turbocharger compression ratio. In fact due to electric power limitations, the operating conditions are moved in the eBooster compressor map along iso-power trajectories, see figure 9. On these trajectories, the compression ratio is reduced as the gas mass flow increases. The turbocharger has therefore to largely offset this boost decrease to elevate the intake pressure. 


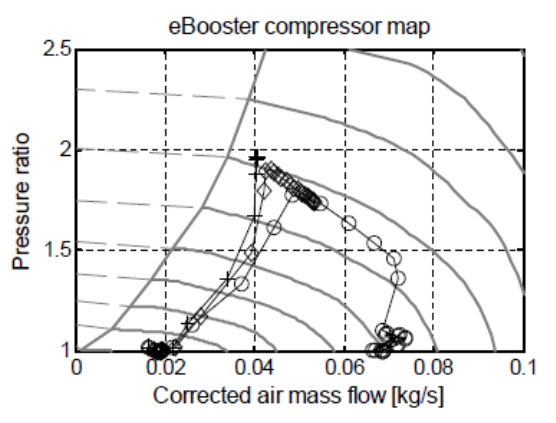

Compressor / turbine map
-2T eBooster $4 \mathrm{~kW}$ Turbine VGT Turbo $0 \%$ (closed)
-2T eBooster $4 \mathrm{~kW}$ Turbine VGT Turbo $50 \%$
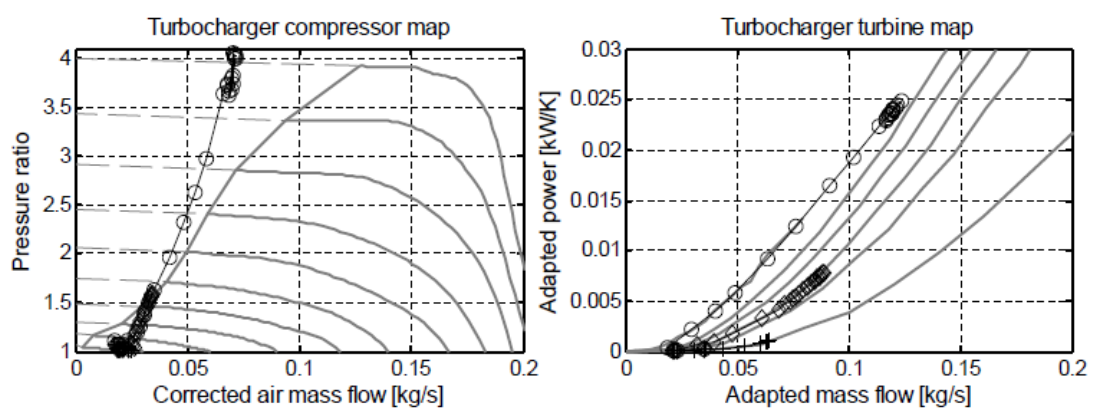

Figure 9: Transient operations plotted in the eBooster and turbocharger characteristics maps as a function of turbocharger boost abilities (cold transient test cycles at 1000rpm on the 2.31 engine). ratio

When $2 \mathrm{~T}$ eBooster architecture is fitted in different engines displacement, the first part of the time response which is mainly controlled by the eBooster characteristics is not dependant of the engine swept volume, as shown in fig- ure 10. Both 20 bar and 30 bar BMEP objectives can thus be reached in approximately 0.5 second on the different downsized engines if the eBooster and vehicle network are designed to the corresponding electric power levels. Otherwise, the eBooster will not produce the entire boost requirements and the time response will result slower according to the turbocharger matching and its abilities to provide the missing compression work.

\subsection{Two Stage Supercharger Architecture}

In a $2 \mathrm{~T}$ supercharger configuration, transient response depends on the transmission ratio, the clutch time delay characteristics and on the turbocharger boost abilities. Without interactions 

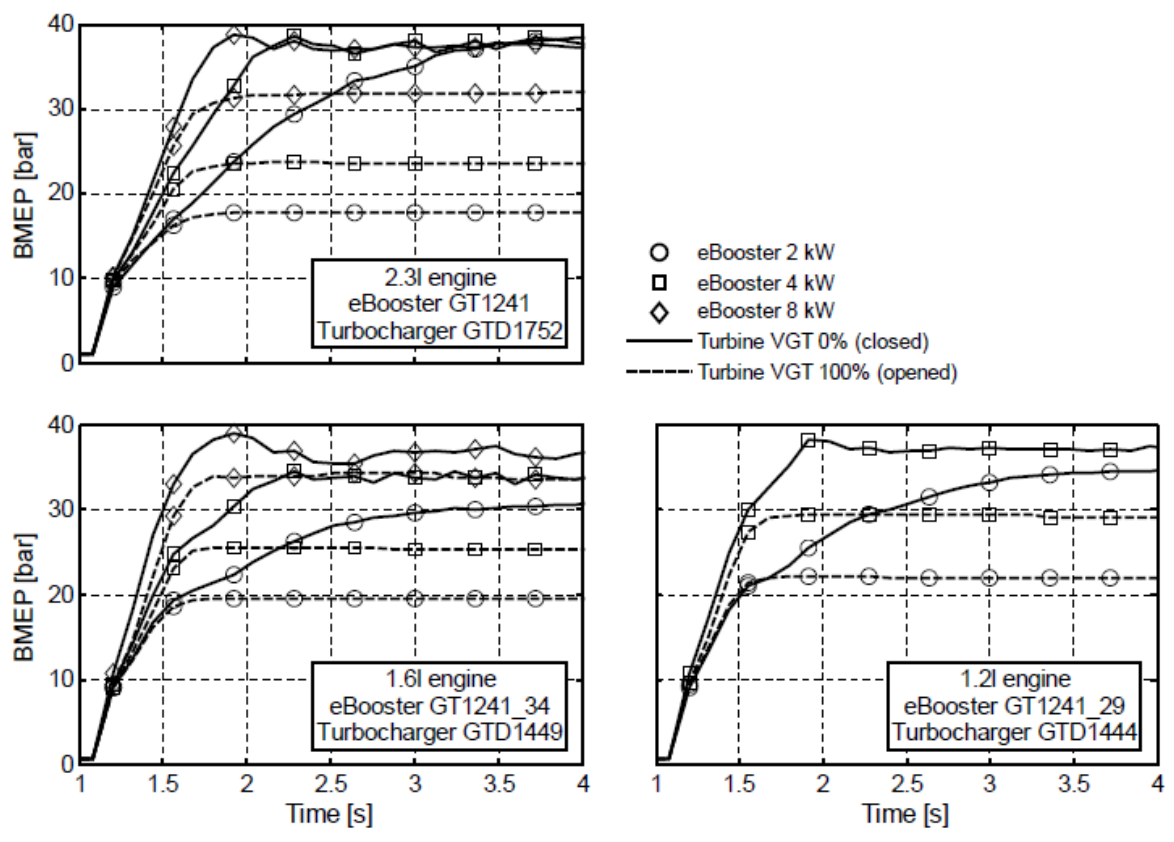

Figure 10: $2 \mathrm{~T}$ eBooster architecture transient responses on different downsized-downspeeded engines as a function of turbocharger boost abilities and electric power levels (cold transient test cycles at $1000 \mathrm{rpm})$.

between the turbomachines in the ex- haust side, the VGT is maintained in a closed position as for the $2 \mathrm{~T}$ eBooster architecture. To analyze the main characteristics of $2 \mathrm{~T}$ supercharger systems responses, simulations have been performed on the 2.31 engine with an Eaton R250 and a like turbocharger(GTD1752). Two different transmission ratios have been selected for the calculations. The first one (rgearbox 13) corresponds to the transmission ratio which maximizes the compression ratio avoiding over- shoots in the supercharger map (2.5 maximum compression ratio). While the second one (rgearbox 10) is relatively smaller to carry out a sensitivity anal- ysis of the transmission ratio. In this second case, the supercharger runs at lower speeds with a maximum compression ratio of 2 during the transient. For supercharger engagement, a progressive activation time of 0.3 second has been retained to reproduce the behavior of typical electromagnetic particle clutch or plate type friction clutch $[146,175]$. The obtained results are shown in figures 11-12 where VGT positions have also been varied to represent different 

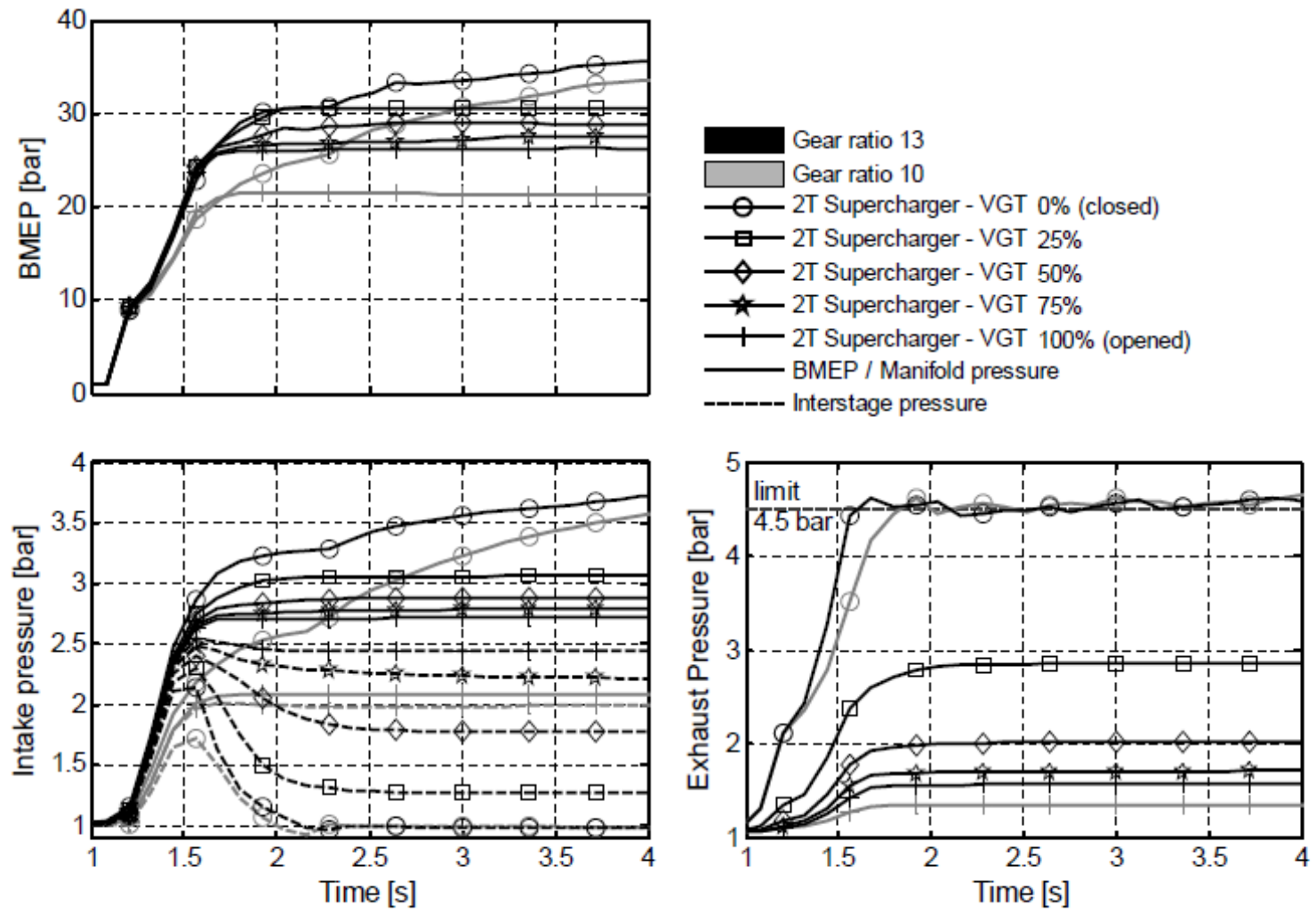

Figure 11: 2T eBooster architecture transient responses on different downsized-downspeeded engines as a function of turbocharger boost abilities and electric power levels (cold transient test cycles at 1000rpm).

turbocharger boost abilities.

In figure 11, it can be seen the supercharger provides directly at the end of its activation time the maximum boost corresponding to the transmission ratio. The first part of the transient is thus characterized by the clutch per-formance and the choice of the transmission ratio which is crucial to reach the low-end torque objectives. In the second part, as for the $2 \mathrm{~T}$ eBooster configu- ration, the turbocharger can continue to accelerate according to its efficiencies, inertia and swallowing capacity. However, the intake pressure increase is much more limited here despite high reachable turbocharger compression ratios. In fact, the supercharger is a volumetric machine which runs during this tran- sient test cycle at constant speed (rgearboxNmot). Being 

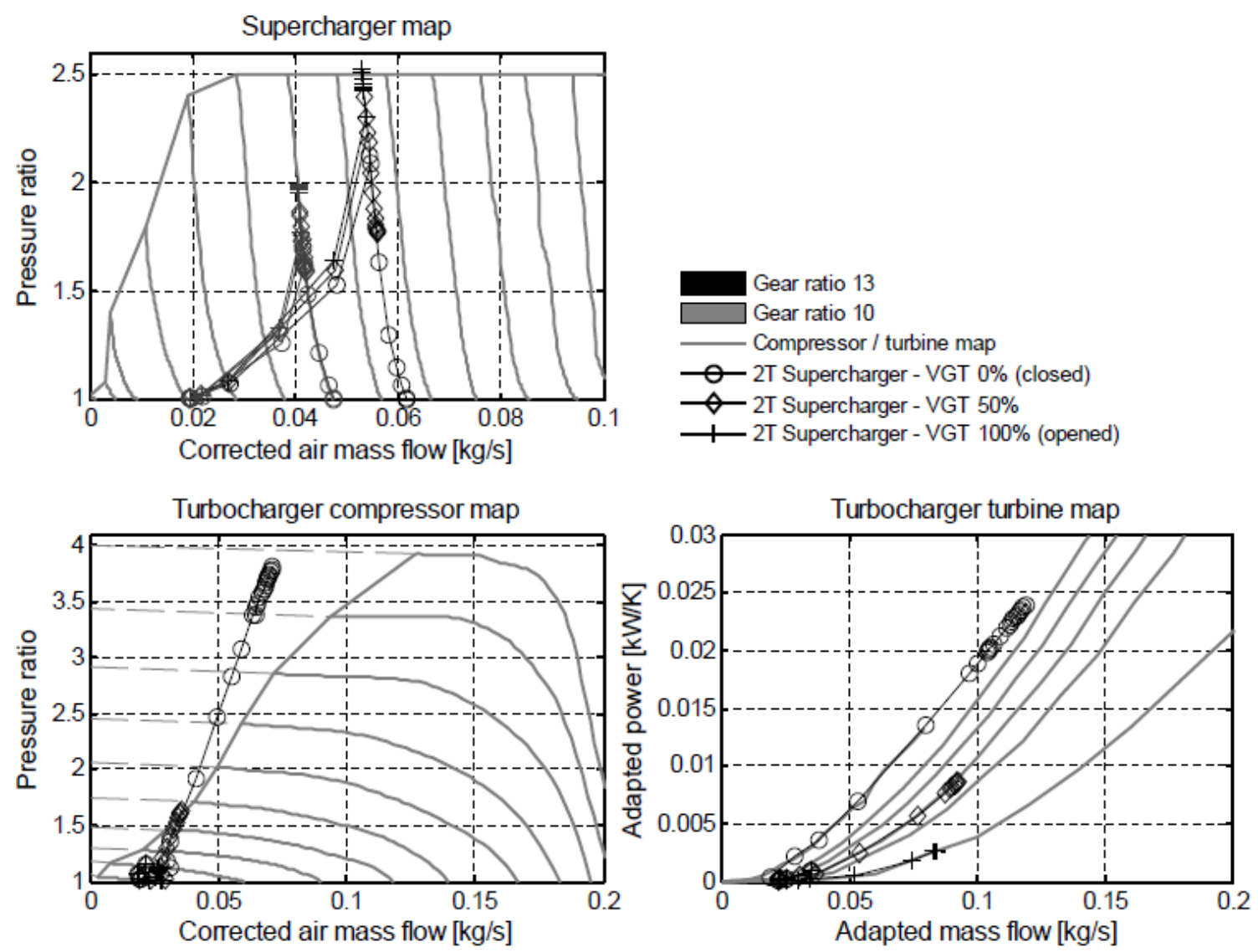

Figure 12: Transient operations plotted in the supercharger and turbocharger characteristics maps as a function of gear ratio and turbocharger boost abilities (cold transient test cycles at 1000rpm on the 2.31 engine).

placed upstream the turbocharger, there is no significant air density variation at its inlet. The gas volumetric flows and the corresponding gas mass flows are thus relatively constant. Only a slight increase can be observed in the supercharger map (figure 12) as the compression ratio decreases due to lower internal losses.

So when the turbocharger accelerates and produces some boost, the gas mass flow is strongly restricted by the supercharger volumetric capacity and the supercharger compression ratio is reduced creating certain equilibrium between both chargers. Until completely offsetting this boost decrease to disengage the supercharger, the intake pressure can only suffer small variations and 

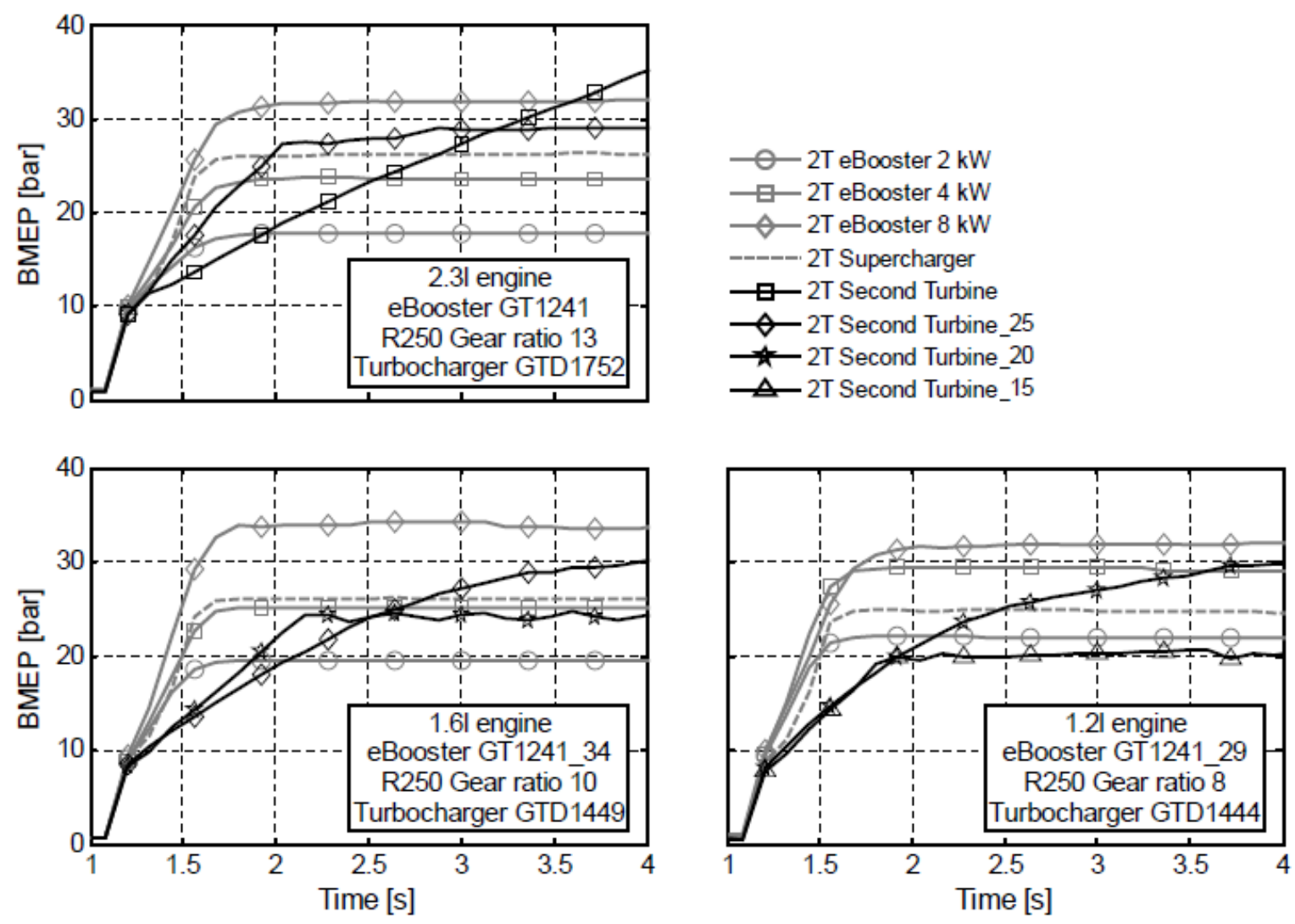

Figure 13: Synthesis of 2-Stage architecture transient performance on different downsizeddownspeeded engines during cold transient test cycles at 1000rpm.

the BMEP increases noticed in figure 11 are the result of both slightly higher gas mass flows and lower supercharger brake power consumptions.

With the same Eaton supercharger, the time responses obtained for the other engine displacements are shown in figure 13. In each case, the trans- mission ratio has been optimized to maximize the supercharger compression ratio, while the VGT has been maintained fully open to reproduce typical matching (limited turbocharger boosting abilities at low speeds). As it can be observed with this boosting architecture, an objective of 20 bar BMEP can be reached in approximately 0.5 second independently of the engine swept vol- ume. Only the transmission ratio has to be reduced to adapt the supercharger speed to the low-end torque requirement. For 
an objective of 30 bar BMEP, as already explained, the current designs with maximum compression ratio of 2.5 do not allow this power level to be reached. But if new superchargers able to work under high compression ratios are developed, the same fast transient responses will be achieved.

In figure 13, the results obtained with the other architectures have also been plotted to analyze the different systems. Having almost instantaneous time responses, the transient performance of $2 \mathrm{~T}$ supercharger and $2 \mathrm{~T}$ eBooster configurations are obviously quite similar. However the time responses of $2 \mathrm{~T}$ turbocharging architectures are slower and turbo-lags make performance objectives of 1 second quite challenging on the smaller engine displacements. The final architecture selection will thus depend on the future development of small high efficient turbochargers and, if these turbochargers are not available, the choice between the $2 \mathrm{~T}$ supercharger and $2 \mathrm{~T}$ eBooster systems will depend on the evolution of vehicle architecture electrification.

\subsection{Conclusion}

In transient operations, the turbo-lag of small turbochargers has first been characterized with sensibility studies on turbine size, shaft inertia and tur- bocharger efficiencies. Then, the other specific factors affecting transient responses such as eBooster characteristics, supercharger transmission ratio, clutch delay time, etc. . . have been analyzed putting special emphasis on con- trol strategies and main turbocharger boosting abilities at low speeds. Finally, an architecture comparison has been carried out on different downsized engines to determine the greatest transient performance that can be achieved with ad- vanced charging systems. In this chapter, most of the obtained conclusions play an integral part of the thesis contributions. So for the sake of brevity, only a summary of the performed analyses have been given here and all the corresponding conclusions have been directly reported in the following chapter specifically devoted to this purpose. 


\section{References and Notes}

1. Carlo Beatrice, Giovanni Avolio, Nicola Del Giacomo, and Chiara Guido. Compression ratio influence on the performance of an advanced single-cylinder diesel engine operating in conventional and low temperature combustion mode. Technical report, SAE Technical Paper, 2008.

2. Alberto A Boretti and Giuseppe Cantore. Similarity rules and parametric design of race engines. Technical report, SAE Technical Paper, 2000.

3. Enrico Cacciatori, Baptiste Bonnet, Nicholas D Vaughan, Matthew Burke, David Price, and Krzysztof Wejrzanowski. Regenerative braking strategies for a parallel hybrid powertrain with torque controlled ivt. Technical report, SAE Technical Paper, 2005.

4. G Cantore and E Mattarelli. Similarity rules and parametric design of four stroke motogp engines. Technical report, SAE Technical Paper, 2004.

5. A Chasse, P Moulin, P Gautier, A Albrecht, L Fontvieille, A Guinois, and L Doléac. Double stage turbocharger control strategies development. SAE International Journal of Engines, 1(2008-01-0988):636-646, 2008.

6. G Cipolla, A Vassallo, AE Catania, Ezio Spessa, C Stan, and L Drischmann. Combined application of cfd modeling and pressure-based combustion diagnostics for the development of a low compression ratio high-performance diesel engine. Technical report, SAE Technical Paper, 2007.

7. J Galindo, JR Serrano, C Guardiola, and C Cervelló. Surge limit definition in a specific test bench for the characterization of automotive turbochargers. Experimental Thermal and Fluid Science, 30(5):449-462, 2006. 
8. José Galindo, A Tiseira, FJ Arnau, and R Lang. On-engine measurement of turbocharger surge limit. Experimental Techniques, 37(1):47-54, 2013.

9. Francisco Payri González and José $\mathrm{M}^{\mathrm{a}}$ Desantes Fernández. Motores de combustión interna alternativos. Editorial Universitat Politècnica de València, 2011.

10. Hermann Hiereth and Peter Prenninger. Charging the internal combustion engine. Springer Science \& Business Media, 2007.

11. P Hoecker, JW Jaisle, and S Munz. The ebooster from borgwarner turbo systems-the key component for a new automobile charging system. Borg Warner Turbo Systems Knowledge Library, page 5, 2000.

12. N.Ausserhofer M.Weissbaeck O.Soustelle P.Ragot P. Mallet M.F.Howlett, W.Schnider and J. Rozen. 3 cylinder aggresive downsized diesel. 2010.

13. S Münz, M Schier, HP Schmalzl, and T Bertolini. ebooster design and performance of a innovative electrically driven charging system, 2008.

14. Alexandros Plianos and Richard Stobart. Modeling and control of diesel engines equipped with a two-stage turbo-system. Technical report, SAE Technical Paper, 2008.

15. José Ricardo Hector, Galindo Lucas. Contribución a la Mejora del Margen de Bombeo en Compresores Centrífugos de Sobrealimentación. PhD thesis, 2011.

16. Gino Sovran. The impact of regenerative braking on the powertrain-delivered energy required for vehicle propulsion. Technical report, SAE Technical Paper, 2011.

17. Richard Van Basshuysen and Fred Schäfer. Internal combustion engine handbook-basics, components, systems and perspectives, volume 345. 2004. 
18. G. Oberholz V.Simon and M. Mayer. The Impact of Regenerative Braking on the Powertrain-Delivered Energy Required for Vehicle Propulsion. Bog Warner Turbo System Knowledge Library, 2000.

19. Neil Watson and Marian Stefan Janota. Turbocharging: The internal combustion engine. MacMillan, 1982. 